\title{
Situating Childhood: A Reading of Spatiality in Aboriginal Picture Books
}

\author{
Trish Lunt
}

There is no unspatialized social reality

(Soja 1996, p.46).

\section{Representing spatiality}

Stuart Hall contends that ' $[\mathrm{p}]$ ractices of representation always implicate the positions from which we speak or write-the positions of enunciation'(1996, p.110). I would add that there is a deferred manifestation of positioning in the act of reading. Since, as Hall says, '[w]e all write and speak from a particular place and time, from a history and a culture which is specific...[w] hat we say is always 'in context, positioned' (1996, p.110). The act of reading is also implicated by cultural positioning. For myself, having colonial-immigrant Anglo-Saxon heritage, the act of reading texts by Aboriginal authors is weighted with cultural dilemma: firstly, I feel unqualified to read unfamiliar cultural nuances appropriately; secondly, I fear mis-reading, and mis-appropriating Aboriginal cultural production(s). In an attempt to mediate my own misgivings, I would like to take up Lisa Disch's model of visiting, of which she recommends that ' $[\mathrm{I}] \mathrm{n}$ order to tell yourself the story of an event from an unfamiliar standpoint, you have to position yourself there as yourself' (1994, p.158). So, I approach Aboriginal texts as a visitor, and bring with me the cultural knowledge that I have acquired as educated, white, Australian, female, adult.

In visiting, I will attempt to perform a contemporary reading of spatiality in Aboriginal picture books in terms of representations of inhabitation and spatial phenomena within the text. Bob Randall and Kunyi June-Anne McInerney's Tracker Tjugingji (2003) invites readers to share a journey in and through cultural constructions of spatiality. Elaine Russell's A is for Aunty (2000) creates a montage of performative spatiality that links space and time. Russell's most recent picture book, The Shack That Dad Built (2004) furthers representations of spatiality as personified by embodiment. These texts offer a spatialisation of Australian childhood that invites exploration.

\section{The construction of spatiality}

To borrow from Helen Tiffin, texts construct worlds (1987, p.22). In indigenous Australian cultures, worlds also construct texts, since notions of country are inherent to Aboriginal stories; both stories and people are 'placed' (Bradford 2003, p.202). Furthermore, children's picture books construct worlds perceived by adults (and sometimes children) that further construct representations of worlds played back to children in the acts of production, interpretation, viewing/reading and being-read-to.

Recognition of the nature of constructed worlds calls into being notions of spatiality, since spatiality is the performative affiliation of object and space that Heidegger regarded as 'being-in-the-world' (1962) and is elsewhere described as 'habitus'(Bourdieu 1977), 'lived space'(Lefebvre 1991) or 'dominated space' (Low 2003). Nevertheless, spatiality is a product of the occupancy of space. In The Production of Space (1991) Henri Lefebvre recognizes complementary aspects of spatiality in which space imposes behaviour on the occupant, and simultaneously, the nature of occupation constructs space.

Central to the condition of spatiality is inhabitation. In the 1980 s, during the reconceptualisation of geographies as 'postmodern', Edward Soja condenses Lefebvre's argument in his declaration that, as a 'social product, spatiality is simultaneously the medium and outcome, presupposition and embodiment, of social action and relationship' (1989, p.118). Thus, spatiality can be considered a place and an event, occupation and interaction, with others and with space itself.

Of what value are these Western theoretical insights to an interpretation of spatiality in Aboriginal picture books? Lefebvre (1991) and Soja $(1989,1996)$ provide a position from which culturally constructed theories of spatiality coincide and diverge. While some cultural constructions of spatiality overlap, both divergence and multiplicity are important to post-colonial reconceptualisations of cultural exchange, and establish the persistent becoming of a spatialisation of childhood that incorporates cultural diversity.

\section{Tracking Tjugingji}

The title of Tracker Tjugingji (Randall \& McInerney 2003) offers traces of spatial construction. Cultural appropriations of language intersect at the signifier 'tracker' to call up notions of landscape, movement, indigeneity and colonisation so that tracking is applied as both pathway and pursuit. The reader joins Tjugingji on his adventure. and is carried by the movement of protagonist and narrative. The 
significant direction of movement in this text is forward through the book, crossing boundaries of pagination in the enactment of temporal passage, moving from left to right in concordance with reading practices that equate in the Western scientific imaginary to movement to the East, regardless of the physical position (according to Euclidean spatial geometries) of the book.

The general spatiality of Tracker Tjugingji is, at the surface, the sequentiality of a young child's trek across the desert to meet with his parents. He is assisted on his way by animal tracks in the sand, and by the animals' confirmation of the progressive passage of his parents. It is a chronological journey in which movement incorporates the (implied) reader in the journey. The reader becomes subjected by the text, drawn into the internal spatiality of the book, both from the reading perspective above the page, and as fellow traveller, equally paced with Tjugingji.

While moving along with the boy, the reader also moves in and out from the page - in close to view the sleeping parents, well out from the action (with Tjugingji) as his parents leave the campsite, then closely positioned by Tjugingji for his journey. When Tjugingji remembers ' $\mathrm{Oh}$, that's right, they were heading for the lake', the reader is situated as companion at the boy's right. Sometimes the reader stands behind Tjugingji, such as when he meets the kuniya (snake) and the kalaya (emu). In terms of the reader's physical positioning in the text, it is at the meeting with the kalaya that Tjugingji moves ahead of the reader, so that the reader must follow, becoming observer rather than participant, separated from Tjugingji as he locates and celebrates with his family.

In Tracker Tjugingji, the verbal text is spatialised - set on the page to denote the cadence and tone of oral presentation. Different font sizes invite levels of vocal dynamics in the reading of the text (whether internalized or vocalized) from, for example, the narrator's whispered cue on the first page: '[say chook in gee]', to the exuberant

\section{'Dad, Mum...Come on'}

at the lakeside camp. The visual production of vocal performance positions the narrator as story-teller, and both narrator and reader as inherently spatialised in the construction of the text.
Bold layering of the landscape-deep blue and desert russet - contributes to the physical spatiality of the text. Spatiality is also produced by the filtration of light down the page, suggesting the movement of the sun. The interrelationship of the sun and the sand is captured by the golds and reds on the double spread in which Tjugingji's parents depart and, some time later, Tjugingji awakes. The direction of the light is reversed in the final campfire scene. This spatial construction of the passage of time suggests a layered temporality. Space and time are inseparable, not only in Western science, but in Aboriginal narrative production. This tale is both physical and metaphorical, at once grounded and multiply layered through time and across space. It brings together a contemporary story with the times and places of the history of the Western Desert.

The depiction of tracks on the ground adds another significant layer of spatiality to the text. When Tjugingji discovers that his parents have departed for the lake, he anticipates his role as Tracker (as his role is also preempted by the title of the book, and his name - Tracker Tjugingji) - one who follows the (sometimes almost imperceptible) paths of others: 'Oh well', he says, 'never mind. I'll just follow their tracks.' The verbal text on the pages

where he

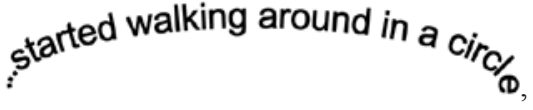

situates the tracks of his parents and dogs running all over the place

is assembled spatially; this placement of verbal text complements the action in the visual text. The act of reading is spatialised; it is no longer merely a cerebral contract between reader and text, but also a physical one. As well as conforming to the left-right conventions of reading, this narrative production requires top-bottom reading of textual layers. The act of narration, then, is constructed in replication of the way in which Indigenous stories might traditionally be spoken and illustrated by hand-drawn markings on the ground, further connecting people and country by the interrelation of text and its production.

Each of the animal guides that assists Tjugingii is introduced in the text (both verbal and visual) by the representation of imprints in the sand: 'After a while [Tjugingji] saw a track 
he knew really well.' Readers who have some knowledge of the Pitjantjatjara language have verbal cues as to the type of animal that made the tracks: 'That's old grandpa kuniya [say coo nee ah]'. Other readers are invited to guess the type of animal that has made the track, by language and by identifying the track or by sighting McInerney's visual prompts provided by representations of animals' tails leading off the page (to the top, or the right). These visual representations - tracks and tails - might also be manifestations of traditional narrative cues drawn on the ground.

By inscribing the land with tracks, Randall and McInerney evoke the function of Aboriginal songlines, spiritual tracks by which Aboriginal people are intrinsically linked to their country. In the same way, the animal guides play a dual role as both contemporary story characters and as traditional spirit guides that are integral to notions of country. Randall and McInerney provide a layered spatiality that incorporates multiple perspectives of space and time. This coexistence of all space and all time is the way in which the Dreaming is omnipresent. In its production in Western literary form, it becomes in effect, a translation.

In terms of cultural production, the characters and objects in the text correspond with a contemporary representation of a Pitjantjatjara cultural experience. This representation of the embodiment of space, of being-in-the-world, is one that is discordant with Western conceptions of spatiality except in the form of the production itself; that is, in the cultural production of the book. It is in the space of literary production (and the implicit codes and conditions of the event of publishing) that Tracker Tjugingji crosses cultural spaces.

\section{Worlds joined apart: A is for Aunty and The Shack that Dad Built}

The composite visual and verbal texts of Elaine Russell's picture books encourage connotations of space and beingin-space that contest binary definitions of spatial cultures as Aboriginal or non-Aboriginal. In A is for Aunty (2000), Russell portrays glimpses of (colonised) life at the Murrin Bridge Mission through the lens of the English alphabet. For the letters of the English alphabet, Russell offers minimalist textual and pictorial narratives that coexist in an elaborate yarn on mission life. Russell's more recent text, The Shack
That Dad Built (2004), is constructed as a commentary on significant places of the narrator's childhood prior to her family's relocation to Murrin Bridge. Both can be read as individual entities or as cross-fertilised performances of personal engagements with place across time.

As in Tracker Tjugingji, The Shack that Dad Builtrecreates a journey through space and time. This journey, however, does not a progress chronologically. It begins - on the title page - with arrival at the 'shack' and then explains the family's relocation from Tingha to La Perouse to Murrin Bridge. It begins before it starts, doubles back on itself, sets scenes out-of-time. The Shack That Dad Built is constructed as a series of tales of significant places in the narrator's early childhood. It is an engagement with space, not time, that holds together the time(s) of childhood.

To borrow further from Lefebvre (1991), Russell's 'moments of presence' convey the inherent spatialisation of social life. This is apparent mostly in the mechanism and design of her illustrations, but also in the narrative structure of the text, both of which convey (to my Westernized I/eye) non-Euclidean geometries. In Russell's texts, spatiality incorporates an appreciation of temporality, which cannot be distinguished from space itself. The spaces of Indigenous history merge with those of the present to connect the conditions of colonial history with 1950s history and contemporary experience.

In Russell's illustrations, the evenly spaced, stylised representations of trees, clouds, dunes, bushes function as iconographic signs, especially in their minimalist style, orderliness, and generalisation of features. The natural environment usually takes more of the page than the built environment. This arrangement makes dwellings stand out from the natural environment. The organisation of the Murrin Bridge Mission, then, can be perceived as a manifestation of invader culture. The order of the natural environment is completely suppressed by the construction of the mission, which poses ironically as an ordered and iconographic group of objects. In the same way, depictions of the interior of houses are geometrically inclined, composed of squares and straight lines. The interior walls in 'Our New Home' (Russell 2004) reach the borders of the page. Small windows allow glimpses of a natural environment that is separated from domestic 
spatiality. This might be read as an indictment of Western culture, a criticism of its disconnection of built and natural environments.

Russell describes, both verbally and visually, relentless indicators of action and movement: racing, running, swimming, fence-building, playing, fishing, communing, travelling. Russell textualises action and functionality as components of spatiality; embodiment is purposeful. This form of movement has implications for the perception of Aboriginal people as constructed by their spatial existence. Functional spaces enable subsistence - fishing, gathering figs and berries, earning the few dollars thrown by tourists from the pier. Living at La Perouse in the 1940s and Murrin Bridge in the 1950s, however, is a condition of indigeneity, not a lifestyle choice. Spatial functionality is culturally constructed. As an event of inhabitation, this alludes to Lefebvre's notion of 'appropriated' spaces - l'espace $v e c ̧ u$ - or the lived experience of spatiality (1991). From the billycart race at ' $A$ ', across land and rivers, to the intimate domestic space at ' $Z$ ', Russell's visual and verbal illustrations of life on the Murrin Bridge mission depict the embodiment of space. Spatiality is that being-in-space.

Visual codes for movement also occur on a metaphorical scale. Each scene is connected to somewhere, by road, river, track, bay. There is a persistent reminder that enclosure is paired with openness. Exits are constructed as a part of entrances. Roads and rivers flow through the illustrations. From the internal view of dwellings, the reader notes that doors and windows are open. In The Shack that Dad Built, Botany Bay always contains its entrance/exit. Always within the limitations of confined spatiality is the potential to move beyond, through, or past. Although Russell's illustrations are inset from the edge of the page, suggesting (by Western convention) a border, all the pictures appear to extend beyond the visible edges. For example, the route of the Lachlan River crosses the ' $\mathrm{R}$ is for River' double spread in $A$ is for Aunty, and appears to extend beyond the edges of both pages. Likewise, in The Shack That Dad Built, the 'biggest backyard in the world' stretches the imagination beyond the borders of the pages. The combined efforts of layering and extension draw the reader out into the world beyond the text. These effects also imply opportunities for movement beyond the physical and cultural frame.
In $A$ is for Aunty, there is a persistent motif of roads intersecting at the colonial centre-at the school, the church, at the centre of the Mission itself. However, these roads also lead out in all four directions, suggesting that the spatiality of the mission - and, therefore, colonialism - does not enclose (forever) the Aboriginal people. The one place in Russell's texts where roads $d o$ end is at the school gates at Murrin Bridge Mission. Significantly, this occurs in both A is for Aunty and The Shack That Dad Built. In relation to the emplacement of children in a social spatiality, the implication here is that Western education is a requirement, and one that disconnects people from country.

The binary operations of openness and closure suggest metaphorical dimensions of postcolonialism conveyed through spatial constructions. Despite strong indicators of colonial subjection in the Murrin Bridge scenes, the church is not the focal point in the ' $\mathrm{M}$ is for Mission' illustration. Set at the top right of the page, it seems to draw all roads towards it, but there are many more points of exit, mostly to the left, suggesting that people are able to move away from the colonial Christianising endeavour. Since spatiality comprises embodiment, it also includes the potential to move out of a spatial centre, into adjacent spatialities. Spatialities, then, by nature, incorporate other spatialities. The centre invites the boundaries; the boundaries are contradicted by the frame. The colonial centre is deferred.

Spatial relations between people and land are both intimate and grand in The Shack That Dad Built. Environments are personal yet contain expansive cultural histories. Russell's illustrations exhibit layers of land, sea and sky. They mostly extend to the horizon. The land is open and accessible. In contrast, the scene in which the narrator describes her childhood experience of 'My Saddest Christmas' is indicative of dislocation and enclosure. Russell's narrator provides a verbal and visual recollection of a Christmas Eve, when:

...my parents took me and my brothers and sisters to nearby Matraville, where a charity was giving away toys to Aboriginal children. It was a very hot day, and the queue was so long. 
I watched lots of kids going home, happy with their dolls and bikes and scooters and toy cars. My heart was set on a doll that said "Mama, Mama". When wefinally reached the head of the queue, the people told my parents that they'd run out of toys.

I cried and cried.

(Russell 2004)

The accompanying illustration resists the pathos of Russell's verbal text. Aboriginal people appear to move slowly from right to left across the doublespread. The direction of movement suggests psychological distress (especially when compared with the excitement and anticipation in the left-to-right movement of the train to Murrin Bridge). A white Santa sits at the far left in a white chair by a white house that starkly contrasts with the grey windowless shack in which the family resides at La Perouse. The formally cultivated garden between the road and the fence reiterates the effects of cultural invasion. The closed, disciplined flowerbeds are physically and culturally distinct from the flowing of natural environments in other illustrations; a symbol of colonisation. Perhaps even the lantana has been domesticated. Flat white colonial fences separate black and white cultures, signify ownership (and dispossession), and represent the colonial condescension of cultural assimilation.

On the other hand, it is possible to interpret some of Russell's fenced enclosures as positive indicators of cross-cultural inhabitation. For example, $A$ is for Aunty's illustrations for ' $\mathrm{F}$ ' and ' $\mathrm{S}$ ' where the focus is on the activity of fencebuilding, fences might otherwise signify an assimilationist adoption of the principles of ownership and (re)possession. Perhaps the fenced Christmas episode in The Shack That Dad Built separates me, the white observer, from the scene. Such uncertainty of meaning draws attention to the shared spatiality of postcolonialism, where objects take on different meanings (signs are displaced from signifiers) because of ongoing cultural interface. The association of Western metaphors in regard to fences as boundaries is not immediately (without consideration) applicable to Russell's text. The cultural appropriation of objects is displaced. Rey Chow says, '[T] he natives are no longer staying in their frames' (1996, p.123). I propose that the frames are being moved, by Aboriginal people, in the main, but not without the submission of the administrators of hegemonic modes of Australian cultural production.

A significant mode of spatiality is configured by Russell's representation of tiers of landscape. Where Tracker Tjugingji splits sky and earth, Russell's 'J \& K' illustration in $A$ is for Aunty, for example, layers sky, bushland, and grassland. Child-observers are positioned at the bottom of the frame, below a middle layer which the native fauna inhabit, and a ceiling of skyscape that maintains a proportional balance of human and natural elements. This notion of layering is extended in The Shack That Dad Built where three distinct but always-connected tiers of landscape exist. Country is comprised of sky, sea and land. In the 'Bush Tucker' and 'Fish for Supper' episodes in The Shack That Dad Built, the tiers of landscape synchronise with layers of action. The environment is at the same time functional (the fishing activity), personal (playing in the dunes) and natural (a constant of sky, sea and land). It is significant that the natural world retains its own share of the picture, its third of the page, despite being uninhabited. Land and people are equally important and inseparable components of spatiality.

In 'P is for Possum', horizontal layers are employed to construct different areas of the bedroom. Domesticity, represented by the bedroom furniture, is drawn to a much larger scale than the narrator and possum. Instead of this working to subordinate the narrator, the illustration can be read from the bottom of the page to the top, setting the focus at the forefront of the picture, and reading 'up'. For a different perspective on spatiality, the reader may hold the book horizontally at the nose and look 'across' the page.

In the flat iconic representational style of the illustrations is a further aspect of layering that is significant to Aboriginal cultural production. This is more easily observed (by I, the non-Aboriginal) in the 'L is for Lagoon' illustration, which shows a number of animal groups, mostly in pairs, making their way to a body of water. Verbal reference in the text to 'the animals' Meeting Place' and the positioning of the animals around the waterhole invite the reader to see an underlay of iconic tracks as would be depicted in the dotpainting motifs of, say, the Papunya community. 
In the layering of visual texts, Russell harmoniously merges Western and Aboriginal modes of representation across time. In the same way that the tracks of Tjugingji can be read to represent multiple perspectives of personal and mythical time, Russell's texts encompass the tracks and traces of the Dreaming spirits that traverse both time and space. These texts operate by connecting different cultural modes of representation to construct the coexistence of people and place, both in terms of indigenous cultural histories and post-colonial reconstructions of the relationship between people and place.

These texts offer representations of spatiality that incorporate an omnipresent cultural history with the embodiment of space. Each is informed by the presence (and history) of the other. Just as linguistic signifiers operate in the positioning of Tjugingji as an Aboriginal tracker, colonized by language and power, La Perouse situates Russell's environment as constructed by the dual histories of indigenous and invader cultures. La Perouse is the site of the first indigenous encounters by the Dharawal nation with British settlers, and represents the European campaign to (re)locate and rename indigenous land. La Perouse first became a mission in the $1880 \mathrm{~s}$. The employment of child protagonists and narrators in these texts adds a further dimension to the layers of social injustice apparent in the texts. The child's voice does not enunciate dispossession and dislocation nor recognise the role of disconnection in the process of inhabitation. The child does not recognise his or her own role as the inhabiting architect of new representations of spatiality.

\section{Childhood as the inhabitation of space}

Kerry Mallan's study of play spaces in Australian picture books (2003) provides a valuable overview of the secret (domestic) spaces of children's play. Her selection of texts for discussion sustains, however, John Stephens' view that '[t]he vast majority of landscapes in Australian picture books are cultivated or 'built' rather than 'natural' (2003, p.v). Randall and McInerney's Tracker Tjugingji, provides an opportunity to view the construction of childhood in the natural environment. For Tjugingji, this comprises an especially Aboriginal experience of being-in-space. Tjugingji's being-in-the-world is one of being-in-all-timeand-space. While the tone of the narrative communicates the fun of childhood engagement, Tjugingji's character also takes on mythic proportions as he follows traditional spirit guides whose essence is explained by the Dreaming which features a complex spatiality that expands and contracts to fit all of time within the breadth of history and the brevity of the present. It is both 'being' and 'becoming' and connects Aboriginal people and country.

Randall and McInerney speak through the cross-cultural medium of the text to inform and reconstruct appreciations of spatiality. While respecting the voice of the child in cultural revision, it is vital, also, to keep in mind the voice of the narrator, who in this text adopts the role of gentle guide. The narrative experience imparts skills and knowledge to both indigenous and non-indigenous children: the particularities of tracking; shared language development (both English and Pitjantjatjara); the growth of independence; engagment with the natural, social and cultural conceptualisations of being. The text is rich in learning. Tjugingji does not make his own way. His construction of spatiality is imposed upon him. The text, however, proposes through the unpretentious voice of the child, alternative modes of spatial construction that blend cultural paradigms and reach into the future of emerging narrative and conceptual formations towards blended realities and cross-cultural subjectivities.

In form and content, Russell's texts also earn a place in the conceptual reconstruction of spatiality. It is clear that the embodiment of space is integral to the condition of beingas-child. In A is for Aunty and The Shack That Dad Built, the spaces the child inhabits are many and varied, from dwellings constructed in indigenous, Western, and mixed forms, to natural environments and built environments, rooms and expanses of country. The child is fundamentally present in space. In $A$ is for Aunty, children inhabit the spaces of games and of learning, of home and of country. Russell depicts children as regularly engaged in the playing of games. They play at school, at home, with the emu chicks and the kangaroos, in the river and across the valleys. The persistent event of this mode of embodiment is play. Where adults are concerned with using the land for subsistence, children secure the ownership of land for play.

Russell's positioning as author and narrator subjectifies the spatiality of the text. These are texts of (her) childhood. In $A$ 
is for Aunty, the narrator appears as a character in the visual text, inhabiting the telling of the duckling episode. This red-haired child-narrator recurs through the text, enacting the scenes depicted by the narrator. This positioning of the narrator within the visual text (as she is in the verbal text) recalls the basic premise of spatiality as the embodiment of space. Within the text, the narrator (and author) reclaims the spaces of her childhood, and retains the Aboriginal heritage of Murrin Bridge mission.

The narrator is clearly identified in The Shack That Dad Built by the specific ordering of characters on the first page: 'There was Mum, Dad, my big sister Violet, my big brothers Fred and Mervyn, me and my little sister Gloria.' Despite the transposition of the parents in the accompanying illustration, the visual identity of each character is clear to the reader. Russell's narrator-self focuses the entire text in relation to the location of her birth, her country. Childhood is the beginning of cultural emplacement.

Western institutions occur in Russell's texts as bounded entities that enclose 'settler' society and exclude indigenous people. Schools, roads, the train station, missions are fenced with white pickets, implying white colonial practices of exclusion. In The Shack That Dad Built, roads generally sculpt a route that passes by the sites remembered by the child narrator. This encloses the narrator within the confines of the La Perouse settlement (as the location of childhood), as do the fences that enclose her at Murrin Bridge and at school. Childhood is delimited. Although scenes appear to extend beyond the physical boundaries of Russell's paintings, this structure of confinement illuminates the child's view of a limited world and the comfort of the small. What lies beyond the space-scapes depicted by the child is the frontier that lies beyond childhood.

Where roads pass, suggesting a separation of the outside from the inside, the indigenous community becomes a tourist destination - communities are separated by social status. Tourists regard indigenous children as exhibits: '[T]hey'd throw coins into the sea and watch the kids dive'. The performance as tourism is also the performance of cultural subversion. Childhood and colonialism are intextricably linked by subjection. Russell's community is isolated just as the gypsy family is. The gypsies are invited into Russell's community, united by their common role as 'strangers in a strange land', represented as closing around the campfire. The depiction of Aboriginal and gypsy families circled around the campfire alludes to traditional social configurations and shared experiences on possession and dispossession.

The spatial construction of childhood is depicted a great deal differently in Russell's texts to that of Randall and McInerney's. Russell's first-person narratorial stance embeds the text in childhood experience; most of the scenes construct children in a child's environment. The reader sees with the eyes of the child. The relentless sense of activity in the text signifies the active role of the child in creating the conditions of spatialisation in her or his own environment. Without the narrator, the places in the text do not exist. Russell's child narrators construct a spatial existence that is at one level entirely personal, for it is the interaction of this figure with this space.

However, Russell's texts, by nature of their production as cultural artefacts, also construct a spatial relationship between people and environment. The bold, iconographic illustrations and short verbal synopses support the construction of the narrator as child. The narrator's observations of domestic subsistence in The Shack That Dad Built impart an unmediated naïvety:

Dad didn't want to live in the mission, though
He preferred to be independent...
One day my father showed us a plant called
Warrigal Greens that was growing wild all around
us. We picked bunches of it and took it home to
Mum. She boileditup and it tasted just likespinach.
Our shack didn't have a kitchen, so Mum did all
the cooking outside over an open fire.
(Russell 2004)

Beyond the child's view of simple, uncluttered, wonderful, endowing space lies displacement. The indicators of poverty and racial discrimination are only partially concealed by the grand Western narratives of the rural idyll: independence, self-sufficiency, connection with nature. The construction of children's work as play - collecting berries and golf balls, diving for coins, stealing fish - subjects the child to the consequences of social histories. This is a text that 
invites close reading, for cultural, political and social constructions of spatiality.

I would like to end (almost), as Russell does in $A$ is for Aunty, at ' $Z$ is for Zinc Ointment', with a view inside Aunty Goldie's house. The reference to zinc ointment conjures the products of cultural exchange. The room, in which tea and ointment are shared, however, excludes me, the reader. As in many of the illustrations through the book, the openness to the sides, the availability of an exit, the community of people engaged in activity, the invitation of light and colour are clear. But once I have entered, I cannot escape. I have become a part of the story, embodied by the spatiality of the text.

\section{De/Re constructing Spatiality}

The combination of the yarning narratives of Aboriginal people with Western publishing conventions provides a space of cultural interchange. What might have been performed orally, depicted 'on the ground' (literally) with symbolic representations is being disseminated more widely by contemporary publishing practices. Aboriginal narrative production spatialises representation not in resistance but by the exchange of artifacts of enculturation.

The displacement of Soja's notion of logocentric ontological space (1996), opens windows of opportunity onto a diversity of cultural paradigms that defers assimilation and invites multiple readings of cultural spatialisations. While it cannot be maintained that the texts selected for discussion are representative of an inclusive Aboriginal culture, these texts provide instances of cultural cross-fertilisation through the performance of narrative and the appropriation of space in literature. Contemporary Aboriginal texts engage with multiple cultural positions that acknowledge colonialism and reappropriate Aboriginal space(s). At the same time, they appropriate Western modes of cultural production and dissemination to move beyond the oppositional modes of marginalization and assimilation to a vibrant, active spatialisation of cultural differences and similarities.

The experience of colonization cannot be eradicated from reading (and writing) consciousness. It is retained in the processes of identity formation, cultural (re)production, and being-in-the-world. The reader inhabits the space of the narrative. Outside the frame, the reader looks on. The reader, then, is colonizer and revisionist participant-object, yet subject - in the reappropriation of spatiality.

The act of reading is as significant as that of writing in the grand narrative of cultural production, and in the personal confluence of becoming. Reading contributes to my own becoming - enculturation is persistent. So is the adventure of visiting.

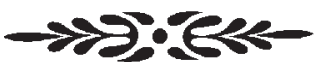




\section{REFERENCES}

Bourdieu, P. (1977) Outline of a Theory of Practice. Cambridge, Cambridge University Press.

Bradford, C. (2003) “ "Oh how different!”: regimes of knowledge in Aboriginal texts for children', The Lion and the Unicorn 27:199217.

Chow, R. (1996) 'Where have all the natives gone?', in P. Mongia (ed) Contemporary Postcolonial Theory: A Reader,.London, Arnold, pp.122-146.

Disch, L.J. (1994) Hannah Arendt and the Limits of Philosophy. Ithaca, Cornwell University Press.

Hall, S. (1996) 'Cultural identity and diaspora', in P. Mongia, op.cit., pp.110-121. Originally published in J. Rutherford (ed) (1990) Identity: Community, Culture, Difference. London, Lawrence \& Wishart, pp.222-237.

Heidegger, M. (1962) Being and Time (trans. J. Macquarie \& E. Robinson). New York, Harper \& Row.

Lefebvre, H. (1991)[1974] The Production of Space (trans. N. Donaldson-Smith). Oxford, Basil Blackwell.

Low, S. (2003) 'Embodied spaces: anthropological theories of body, space, and culture', Space and Culture 6.1: 9-18.

Mallan, K. (2003) 'Secret spaces: creating an aesthetic of imaginative play in Australian picture books', The Lion and the Unicorn 27: 167-184.
Randall, B. \& McInerney, K.J-A. (2003) Tracker Tjugingji. Alice Springs, NT, jukurrpa books $\&$ IAD Press.

Russell, E. (2000) A is for Aunty. Sydney, ABC Books.

Russell, E. (2004) The Shack That Dad Built. Surry Hills, NSW, Little Hare Books.

Soja, E. (1989) Postmodern Geographies: The Reassertion of Space in Critical Social Theory. London, Verso.

Soja, E. (1996) Third Space: Journeys to Los Angeles and Other Real-and-Imagined Places. Oxford, Blackwell.

Stephens, J. (2003) 'Always facing the issues - preoccupations in Australian children's literature', The Lion and the Unicorn 27: v-xvii.

Tiffin, H. (1987) 'Post-colonial literatures and counter-discourse', Kunapipi 9.3: 17-34.

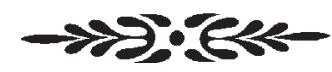

\section{BIOGRAPHICAL NOTE}

Trish Lunt is a sessional tutor in Children's Literature at Deakin University (Burwood campus). After years of effort and adventure, within and beyond the academic frame, she has recently completed an MA (Literary Studies). She has a lingering interest in the science of Umberto Eco, literary constructions of cultural emplacement, and manifestations of evil in fiction for young adults. 